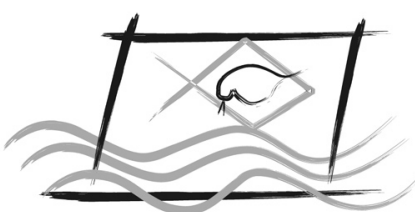

ECOTOX - BRASIL

\title{
Estudos de elementos-traço na cidade de Porto Velho/Rondônia, Amazônia Ocidental
}

\author{
J. Paiva dos Santos ${ }^{1,2}$; D. De Oliveira de Souza ${ }^{1}$; M. Rodrigues Miranda ${ }^{1,3} \&$ W. Rodrigues Bastos ${ }^{1}$ \\ ${ }^{1}$ Laboratório de Biogeoquímica Ambiental Wolfgang C. Pfeiffer, Universidade Federal de Rondônia - UNIR, BR 364, Km 9,5 - Porto \\ Velho, Rondônia. CEP:76815-800. Brasil. http://www.biogeoquimica.unir.br \\ ${ }^{2}$ Secretaria de Estado do Desenvolvimento Ambiental de Rondônia - SEDAM. \\ ${ }^{3}$ Instituto de Pesquisa Translacional em Saúde e Meio Ambiente na Região Amazônica.
}

(Received May 14, 2008; Accept July 02, 2010)

\begin{abstract}
Resumo
A rápida taxa de urbanização associada ao crescimento desordenado tem produzido contínua e sistemática deterioração de sistemas naturais. Os elementos-traço têm sido utilizados como indicadores destes impactos no ambiente. Este estudo teve como objetivo avaliar as concentrações de elementos-traço ( $\mathrm{Fe}, \mathrm{Zn}, \mathrm{Mn}, \mathrm{Pb}, \mathrm{Cu}, \mathrm{Cr}, \mathrm{Co}, \mathrm{Cd}$ e $\mathrm{Hg}$ ) no sedimento superficial de fundo do igarapé dos Tanques, que abrange a área urbana de Porto Velho (Rondônia) e no solo do lixão, que recebe os rejeitos produzidos pelo município. Os valores obtidos evidenciaram que as diversas atividades desenvolvidas nas áreas estudadas influenciaram tanto nas concentrações dos elementos-traço como nas características limnológicas. A análise de componentes principais para as variáveis geoquímicas do sedimento e do solo revelou que o aporte dos elementos-traço ocorre através do carreamento de partículas pelos óxidos de Fe e Mn e através da introdução de efluentes antrópicos no igarapé e da disposição inadequada de resíduos sólidos no lixão.
\end{abstract}

Palavras-chave: Áreas urbanas, contaminação, parâmetros físico-químicos, sedimento, solo.

\section{Trace elements study in the Porto Velho city, Rondônia, Western Amazon}

\begin{abstract}
The fast urbanization process associated with the disordered growth produced a continuous and systematic deterioration of natural systems. The trace elements had been used as indicators of these impacts in the environment. This study evaluated trace elements concentrations ( $\mathrm{Fe}, \mathrm{Zn}, \mathrm{Mn}, \mathrm{Pb}, \mathrm{Cu}, \mathrm{Cr}, \mathrm{Co}, \mathrm{Cd}$ e $\mathrm{Hg}$ ) in bottom surficial sediment of Igarapé (small stream) Tanques that encloses the Porto Velho urban area and municipal waste soil. The results evidenced that the diverse activities developed in investigated areas influenced the trace elements concentrations and limnological characteristics. The principal component analysis to the sediment and soil geochemical variables, demonstrated that the domestic effluents input into igarapé and solid waste inappropriate disposal contributed to trace elements increase. In addition, a trace element input occurs also throughout particles displacement by $\mathrm{Fe}$ and Mn oxides.
\end{abstract}

Key-Words: Urban areas, contamination, physical-chemicals parameters, bottom sediment, soil. 


\section{INTRODUÇÃO}

A partir da década de 70 o estado de Rondônia sofreu um intenso processo de ocupação territorial através de uma política do Governo Federal visando a implantação de diversos projetos de colonização na região, tais como o Programa de Desenvolvimento da Região Noroeste do Brasil (Polonoroeste) e o Plano Agropecuário e Florestal de Rondônia (Planafloro). Uma das justificativas balizadoras desta política interna visava a diminuição de tensões sociais na região sul e centro-sul do Brasil. Um dos resultados imediatos desta política de imigração resultou no expressivo aumento das taxas de desflorestamento, com efeitos deletérios para os ecossistemas e as populações tradicionais (Pedlowski et al., 1999).

Outro fator que contribuiu para o aumento do contingente populacional foi o início do processo de extração artesanal do ouro que atingiu seu pico no final da década de 80 , com o estabelecimento das primeiras dragas no alto rio Madeira (Adamy \& Pereira, 1991). Nesse cenário, foram instaladas na região pequenas metalúrgicas para confecções de balsas e dragas e outros empreendimentos que se desenvolveram a partir do processo de exploração do ouro.

Como conseqüência imediata deste processo de ocupação desordenada e sem critérios técnico-científicos, o município de Porto Velho passou por um processo de crescimento rápido e desordenado, não recebendo a mesma velocidade pelo Poder Público de investimentos nas obras de infraestrutura. Diante disso, os reflexos ambientais mais evidentes referem-se à escassez de saneamento básico, ausência de tratamento de dejetos domésticos e industriais, disposição inadequada de resíduos sólidos e deficiência dos serviços básicos. A associação destes fatores ocasionou a degradação dos ambientes naturais devido a introdução de diversos contaminantes, dentre os quais destacam-se os elementos-traço.

Os elementos-traço estão presentes naturalmente em solos e em sistemas aquáticos superficiais. $\mathrm{O}$ aumento da concentração de tais elementos pode ocorrer tanto em razão de processos naturais quanto por atividades antropogênicas. Os elementos-traço não são degradáveis e sim transformáveis quimicamente dependendo das condições físico-químicas e biológicas do meio, podendo acumular-se nos diversos compartimentos ambientais, sendo que os locais de fixação final são os solos e sedimentos (Yabe \& Oliveira, 1998; Baird, 2002).

Nas últimas décadas, a poluição de solo e ambientes aquáticos por esses elementos químicos tem merecido especial atenção, sendo reconhecida como um problema que pode trazer danos à saúde e à qualidade ambiental. Diante disso, diversos pesquisadores (e.g., Sisinno \& Moreira, 1996; Robaina, 2002; Bonotto \& Silveira, 2003; Ezaki et al., 2003; Jesus et al., 2004; Hypolito \& Nascimento, 2004) têm realizado estudos com o objetivo de quantificar os níveis desses elementos em ambientes potencialmente contaminados, determinando e identificando as possíveis fontes de poluição.

A partir do atual quadro ambiental, o presente estudo apresenta como objetivo central avaliar a concentração de elementos-traço $\mathrm{Hg}, \mathrm{Cr}, \mathrm{Pb}, \mathrm{Cd}, \mathrm{Cu}, \mathrm{Fe}, \mathrm{Zn}, \mathrm{Mn}$ e $\mathrm{Co}$ em amostras de solo e sedimento da cidade de Porto Velho - RO, uma vez que esses são úteis na identificação, no monitoramento e no controle de fontes de poluição.

\section{MATERIAL E MÉTODOS}

\section{Área de estudo}

Foram escolhidos dois locais para amostragem na cidade de Porto Velho, referentes ao igarapé dos Tanques e ao Lixão Municipal (Fig. 1). Estas áreas despertam interesse porque diversas famílias vivem nas adjacências destes e estão vulneráveis às consequências negativas ocasionadas pela crescente degradação ambiental. O igarapé dos Tanques abrange a área urbana de Porto Velho, sendo o principal receptor de diversos rejeitos domésticos. O Lixão Municipal, que está situado na zona rural, recebe os resíduos sólidos produzidos dentro da área urbana da capital.

O igarapé dos Tanques abrange aproximadamente 23,45 $\mathrm{km}^{2}$, percorrendo uma distância de aproximadamente 10,8 $\mathrm{km}$ de extensão, passando por bairros centrais e periféricos da zona urbana de Porto Velho. Limita-se a Oeste com o rio Madeira (63 $55^{\prime} 03^{\prime \prime} ; 08^{\circ} 43^{\prime} 58^{\prime \prime}$ ) e ao Norte com o bairro Nova Porto Velho (63 52'.42"; $08^{\circ} 45^{\prime}$ 59”).

O terreno utilizado para deposição do lixo urbano de Porto Velho está localizado entre as coordenadas geográficas

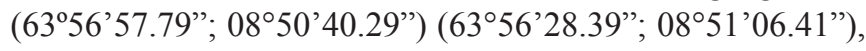
à margem direita da BR-364, sentido Rio Branco, à $13 \mathrm{~km}$ do trevo de acesso a Porto Velho, denominado "Trevo do Roque". A localização e as coordenadas dos pontos de amostragem no igarapé dos Tanques e no lixão de Porto Velho encontram-se na tabela 1 .

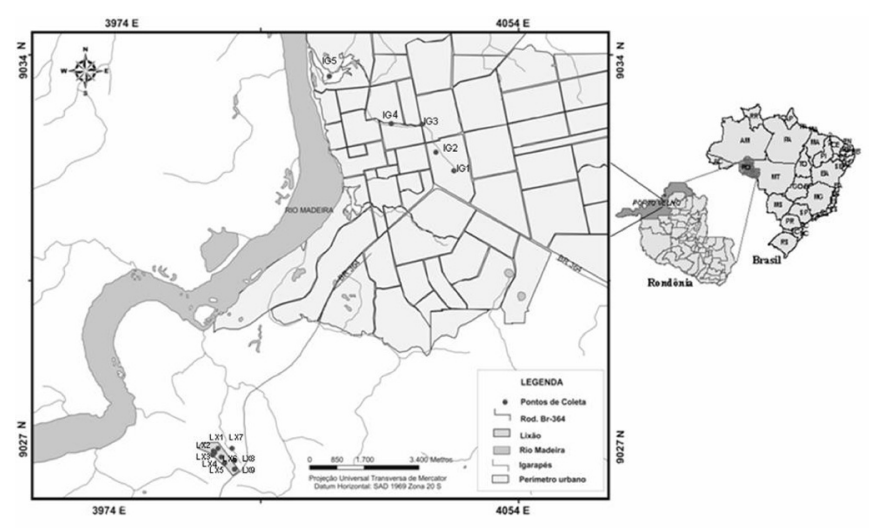

Figura 1. Área de estudo evidenciando os pontos de coleta no igarapé dos Tanques (IG) e na Lixeira Urbana do Município de Porto Velho (LX). 
Tabela 1. Localização e coordenadas dos pontos de amostragem no igarapé dos Tanques e no lixão de Porto Velho.

\begin{tabular}{llll}
\hline & \multicolumn{3}{c}{ Igarapé dos Tanques } \\
\hline Pontos & Longitude & Latitude & Localidade \\
\hline IG1 & $63^{\circ} 52^{\prime} 44.3^{\prime \prime}$ & $08^{\circ} 45^{\prime} 56.3^{\prime \prime}$ & R.: Nicarágua \\
\hline IG2 & $63^{\circ} 53^{\prime} 00.7^{\prime \prime}$ & $08^{\circ} 45^{\prime} 40.8^{\prime \prime}$ & João Pedro da Rocha \\
\hline IG3 & $63^{\circ} 53^{\prime} 15.0^{\prime \prime}$ & $08^{\circ} 45^{\prime} 12.8^{\prime \prime}$ & Av.: Jorge Texeira \\
\hline IG4 & $63^{\circ} 53^{\prime} 45.9^{\prime \prime} 08^{\circ} 45^{\prime} 11.9^{\prime \prime}$ & R.: Salgado Filho \\
\hline IG5 & $63^{\circ} 54^{\prime} 48.5^{\prime \prime}$ & $08^{\circ} 44^{\prime} 23.8^{\prime \prime}$ & Bairro Nacional \\
\hline LX1 & $63^{\circ} 56^{\prime} 47.4^{\prime \prime}$ & $08^{\circ} 50^{\prime} 41.8^{\prime \prime}$ & Área inativa \\
LX2 & $63^{\circ} 56^{\prime} 46.3^{\prime \prime}$ & $08^{\circ} 50^{\prime} 43.6^{\prime \prime}$ & Cavidade \\
LX3 & $63^{\circ} 56^{\prime} 48.3^{\prime \prime}$ & $08^{\circ} 50^{\prime} 45.9^{\prime \prime}$ & Cavidade \\
LX4 & $63^{\circ} 56^{\prime} 42.9^{\prime \prime}$ & $08^{\circ} 50^{\prime} 39.6^{\prime \prime}$ & Área inativa \\
LX5 & $63^{\circ} 56^{\prime \prime} 39.4^{\prime \prime}$ & $08^{\circ} 50^{\prime} 48.2^{\prime \prime}$ & Área próxima à célula ativa \\
LX6 & $63^{\circ} 56^{\prime} 35.6^{\prime \prime}$ & $08^{\circ} 50^{\prime} 54.3^{\prime \prime}$ & Área inativa \\
LX7 & $63^{\circ} 56^{\prime} 28.4^{\prime \prime}$ & $08^{\circ} 50^{\prime} 39.5^{\prime \prime}$ & Solo do sítio adjacente ao lixão \\
LX8 & $63^{\circ} 56^{\prime} 25.5^{\prime \prime}$ & $08^{\circ} 50^{\prime} 51.9^{\prime \prime}$ & $\begin{array}{l}\text { Casa da Vila Princesa, comunidade } \\
\text { que vive às margens do lixão. }\end{array}$ \\
\hline $63^{\circ} 56^{\prime} 25.8^{\prime \prime}$ & $08^{\circ} 51^{\prime} 00.0^{\prime \prime}$ & Casa da Vila Princesa \\
\hline
\end{tabular}

\section{Coleta e preservação das amostras}

A amostragem no igarapé dos Tanques foi realizada nos meses de janeiro (período chuvoso) e novembro 2005 (período de seca) e na lixeira urbana de Porto Velho, a coleta foi efetuada nos meses de outubro de 2005 (período de seca) e maio de 2006 (período chuvoso). Os 14 pontos amostrados nestas áreas foram georreferenciados utilizando um receptor de GPS (Garmin's, mod. GPS 12 xl Personal Navigatior tm) (Tabela 1).

As amostras de solo foram manipuladas com uso de trado holandês, coletando-se a fração entre 0 a $20 \mathrm{~cm}$ e armazenadas em sacos plásticos. O sedimento superficial de fundo foi coletado com draga de Eckman (Cetesb, 1987), armazenado em sacos plásticos e refrigerado $\left(<5^{\circ} \mathrm{C}\right)$ até a análise. As amostras de água foram coletadas e armazenadas em galões de polietileno de $5 \mathrm{~L}$ previamente descontaminados com $\mathrm{HNO}_{3}$ (Cetesb, 1987). Os parâmetros físico-químicos (pH, condutividade elétrica, oxigênio dissolvido e temperatura) foram medidos "in loco", no epilímnio a $20 \mathrm{~cm}$ de profundidade, utilizando condutivímetro (Schott - hand-held conductivity meter-handylablf1), pHmêtro (Schott $-\mathrm{ph} / \mathrm{mv}$ meter-handylab1) e oxímetro (Schott - dissolved oxygen meter-handylab ox1) portáteis.

\section{Preparação e análise}

Os elementos amostrais (solos e sedimentos) passaram por um processo gravimétrico de separação (peneiração a úmido), reduzindo-os a uma fração menor que $0,075 \mathrm{~mm}$ ou 200 mesh. Em seguida foram secos em estufa a $60^{\circ} \mathrm{C}$ por 48 horas e macerados em cadinhos de porcelana (Siqueira et al., 2006). Do material macerado retirou-se uma alíquota de $1 \mathrm{~g}$ em duplicata para a extração química.

A extração química das amostras para quantificação de $\mathrm{Hg}$ e dos demais elementos-traço é realizada de acordo com os métodos utilizados por Bastos et al. (1998), Sastre et al. (2002) e Jesus et al. (2004). Para a quantificação do mercúrio $(\mathrm{Hg})$, as amostras foram solubilizadas com $5 \mathrm{~mL}$ de água régia $\left(\mathrm{HCl}: \mathrm{HNO}_{3} 3: 1\right)$ e posteriormente 8 $\mathrm{mL}$ de permanganato de potássio $\left(\mathrm{KMnO}_{4}\right)$ a $5 \%$ em bloco digestor a $65^{\circ} \mathrm{C}$. A solução ficou em repouso por 12 horas e em seguida foi feita a neutralização com cloridrato de hidroxilamina $\left(\mathrm{HONH}_{3} \mathrm{Cl}+\mathrm{NaCl}\right)$ a $12 \%$. Para a quantificação dos demais elementos-traço, as amostras foram digeridas em chapa quente com $10 \mathrm{~mL}$ de $\mathrm{HNO}_{3} 65 \%$ por 45 min, mais 3 $\mathrm{mL}$ de $\mathrm{H}_{2} \mathrm{O}_{2} 30 \%$ por 15 min e mais $6 \mathrm{~mL}$ de $\mathrm{HCl} 37 \%$. As soluções foram filtradas em papel quantitativo (Whatmam 44) e acondicionadas em tubos de teflon. O volume final de $12 \mathrm{~mL}$ foi aferido com $\mathrm{HCl} 0,1 \mathrm{~N}$.

As amostras foram analisadas acompanhadas de uma amostra de branco e amostras de referência certificadas (IAEA-356 e IAEA-405) (Tabela 2). A quantificação dos teores dos elementos-traço $(\mathrm{Cr}, \mathrm{Pb}, \mathrm{Cd}, \mathrm{Cu}, \mathrm{Fe}, \mathrm{Zn}, \mathrm{Mn}$ e Co) foi realizada por espectrofotometria de absorção atômica por chama (AAS - Atomic Absorption Spectrophotometry GBC-AVANTA, Modelo-3000). A determinação de Hg foi realizada por AAS com sistema de injeção em fluxo (Flow Injection Mercury system, FIMS 400 - Perkin Elmer).

\section{Análise dos dados}

As variáveis obtidas neste estudo seguiram dois tratamentos complementares: Análise descritiva e análise multivariada por técnica de ordenação (Análise de Componentes Principais).

Tabela 2. Controle de qualidade analítica utilizando amostras de referência certificadas IAEA-356 e IAEA-405.

\begin{tabular}{ccccc}
\hline $\begin{array}{c}\text { Amostra } \\
\text { referência }\end{array}$ & \multicolumn{2}{c}{ Valor de referência } & \multicolumn{2}{c}{$\begin{array}{c}\text { Valor do lab. de } \\
\text { biogeoquímica } \\
\text { (UNIR) }\end{array}$} \\
\hline & $\begin{array}{c}\text { Média } \\
\left(\mathrm{mg} \mathrm{kg}^{-1}\right)\end{array}$ & $\begin{array}{c}\text { Intervalo de } \\
\text { confiança } \\
\left(\mathrm{mg} \mathrm{kg}^{-1}\right)\end{array}$ & $\begin{array}{c}\text { Média } \\
\left(\mathrm{mg} \mathrm{kg}^{-1}\right)\end{array}$ & $\begin{array}{c}\text { Erro } \\
\text { relativo } \\
(\%)\end{array}$ \\
\hline IAEA 405- Fe & 37.400 & $36.700-38.100$ & 32.043 & 14,3 \\
IAEA 356- Pb & 347 & $301-365$ & 343 & 1,01 \\
IAEA 356- Cu & 365 & $351-375$ & 318 & 12,7 \\
IAEA 405- Mn & 495 & $484-506$ & 516 & 4,24 \\
IAEA 405- Zn & 279 & $272-286$ & 310 & 11,4 \\
IAEA 356- Co & 15 & $14,1-16,4$ & 15,8 & 5,60 \\
IAEA 405 - Hg & 0,81 & $0,77-0,85$ & 0,86 & 6,17 \\
\hline
\end{tabular}


$\mathrm{Na}$ análise descritiva foram registrados os valores médios, o desvio padrão e o coeficiente de variação. Estes parâmetros foram necessários a fim de resumir e gerar regularidades nos dados obtidos e na evidência de padrões que permitissem a realização de interpretações iniciais dos resultados.

Já a análise multivariada teve como objetivo ordenar e analisar os dados com base nos padrões evidenciados. Para tanto foi utilizada neste estudo a Análise de Componentes Principais (ACP). De acordo com Landim (1998) e Bernardi et al. (2001), esta técnica vem sendo utilizada com bastante relevância para ordenação e redução do número de variáveis e para fornecer uma visão privilegiada dos principais padrões de variação do conjunto de dados, sendo bastante utilizada na área ambiental.

\section{RESULTADOS}

\section{Análise descritiva}

Os resultados dos parâmetros físico-químicos medidos nas águas do igarapé dos Tanques encontram-se expostos na tabela 3. Observou-se que houve uma variação na temperatura da água, sendo os maiores valores encontrados durante o período de seca, caracterizando uma temperatura típica de regiões tropicais e de rios da região Amazônica (Sioli, 1991). Os maiores valores de condutividade elétrica foram registrados durante o período de seca e o $\mathrm{pH}$ apresentou valores mais elevados nesse período, com exceção do ponto IG2. Os maiores valores de oxigênio dissolvido foram registrados durante o período chuvoso.

Os resultados obtidos das concentrações de elementostraço em sedimento encontram-se expostos na tabela 4. Os referentes ao ponto IG 4 não foram utilizados, visto que o sedimento foi coletado somente em um período sazonal. No período de cheia, as maiores concentrações foram dos elementos $\mathrm{Cr}, \mathrm{Pb}, \mathrm{Cd}, \mathrm{Cu}$ e $\mathrm{Co}$, enquanto que no período de seca as maiores concentrações foram registradas para os elementos Fe, Zn, Mn e Hg. É interessante ressaltar que a concentração do elemento $\mathrm{Fe}$ aumentou no período de seca, o que pode ter contribuído para o aumento da condutividade elétrica nas águas do igarapé.

A tabela 5 expõe os resultados obtidos nas análises de elementos-traço no solo do lixão. Observa-se que a concentração média de todos os elementos foi maior no período chuvoso (com exceção do Fe). Os elementos que apresentaram as maiores médias tanto no período de seca como no período chuvoso foram o $\mathrm{Zn}$ e o Fe, sendo que o último apresentou as maiores concentrações em todos os pontos nos dois períodos sazonais. Os teores mais elevados da maioria dos elementos (exceto $\mathrm{Cr}$ e $\mathrm{Fe}$ ) durante o período de seca foram encontrados no ponto LX 9 e no período chuvoso, as concentrações mais elevadas de todos os elementos foram observadas no ponto LX 4 (exceto Mn).

\section{Análise de Componentes Principais (ACP)}

Para as variáveis físico-químicas e geoquímicas de sedimento de fundo foi realizada a ACP utilizando os dados dos dois períodos sazonais e para as variáveis geoquímicas do solo foi realizada uma ACP para cada período.

A tabela 6 apresenta a porcentagem de variância explicada obtida para as três primeiras componentes, bem como a contribuição de cada variável físico-química (loadings). A ACP ordenou as duas principais componentes, obtendo-se um total de $72,70 \%$ da variância explicada.

$\mathrm{Na}$ ACP para as variáveis geoquímicas do sedimento superficial de fundo, o elemento $\mathrm{Cd}$ não foi utilizado por estar abaixo do limite de detecção da técnica (LDT). A ACP ordenou as duas principais componentes, obtendo-se um total de $83,40 \%$ da variância explicada (Tabela 7).

Na tabela 8 observou-se a porcentagem da variância explicada para as componentes principais e a contribuição

Tabela 3. Resultados dos parâmetros físico-químicos na água no período chuvoso e de seca no igarapé dos Tanques. $\bar{x}$ : Média; DP: desvio padrão; CV: coeficiente de variação.

\begin{tabular}{|c|c|c|c|c|c|c|c|c|c|}
\hline Parâmetros físico-químicos & Período & IG1 & IG2 & IG3 & IG4 & IG5 & $\bar{x}$ & $\pm \mathrm{DP}$ & CV \\
\hline \multirow{2}{*}{ Temperatura $\left({ }^{\circ} \mathrm{C}\right)$} & Chuva & 27,0 & 28,5 & 29,2 & 29,6 & 29,5 & 28,8 & 1,10 & 3,70 \\
\hline & Seca & 36,6 & 37,5 & 36,5 & 33,0 & 33,4 & 35,4 & 1,80 & 5,20 \\
\hline \multirow{2}{*}{$\mathrm{pH}$} & Chuva & 6,00 & 5,90 & 6,20 & 3,30 & 6,20 & 5,50 & 1,10 & 20,2 \\
\hline & Seca & 6,80 & 3,70 & 6,90 & 7,10 & 6,80 & 6,30 & 1,30 & 20,5 \\
\hline \multirow{2}{*}{ Condutividade elétrica $\left(\mu \mathrm{S} \mathrm{cm}^{-1}\right)$} & Chuva & 225 & 165 & 166 & 203 & 133 & 178 & 32,2 & 18,0 \\
\hline & Seca & 306 & 292 & 296 & 340 & 250 & 296 & 28,9 & 9,70 \\
\hline \multirow{2}{*}{ Oxigênio dissolvido (mg L-1) } & Chuva & 0,50 & 1,10 & 1,40 & 1,20 & 0,30 & 0,90 & 0,40 & 47,1 \\
\hline & Seca & 1,30 & 0,20 & 0,20 & 0,30 & 1,20 & 0,60 & 0,50 & 78,2 \\
\hline
\end{tabular}


Tabela 4. Resultados das concentrações de elementos-traço no sedimento superficial de fundo, coletado no igarapé dos Tanques no período chuvoso e de seca. $\bar{x}$ : Média; DP: desvio padrão. CV: coeficiente de variação.

\begin{tabular}{|c|c|c|c|c|c|c|c|c|}
\hline $\begin{array}{l}\text { Elementos- } \\
\text { traço }\left(\mathrm{mg} \mathrm{kg}^{-1}\right)\end{array}$ & Período & IG1 & IG2 & IG3 & IG5 & $\bar{x}$ & $\pm \mathbf{D P}$ & $\mathrm{CV}$ \\
\hline \multirow{2}{*}{$\mathrm{Cd}$} & Seca & $<\mathrm{LDT}$ & $<\mathrm{LDT}$ & $<\mathrm{LDT}$ & $<\mathrm{LDT}$ & - & - & - \\
\hline & Chuva & 0,74 & 0,51 & 0,84 & 0,47 & 0,64 & 0,20 & 27,9 \\
\hline \multirow{2}{*}{ Co } & Seca & 1,44 & 0,70 & 0,60 & 0,19 & 0,73 & 0,50 & 71,1 \\
\hline & Chuva & 1,95 & 1,89 & 3,06 & 1,62 & 2,13 & 0,60 & 29,9 \\
\hline \multirow{2}{*}{$\mathrm{Cu}$} & Seca & 44,4 & 59,0 & 22,8 & 6,50 & 33,2 & 23,2 & 69,8 \\
\hline & Chuva & 32,0 & 32,2 & 52,8 & 17,5 & 33,6 & 14,5 & 43,2 \\
\hline \multirow{2}{*}{$\mathrm{Pb}$} & Seca & 30,0 & 15,8 & 19,2 & 7,67 & 18,2 & 9,20 & 50,8 \\
\hline & Chuva & 15,6 & 17,6 & 29,6 & 16,6 & 19,8 & 6,50 & 32,9 \\
\hline \multirow{2}{*}{$\mathrm{Cr}$} & Seca & 68,2 & 65,8 & 47,5 & 25,1 & 51,7 & 20,0 & 38,6 \\
\hline & Chuva & 97,3 & 150 & 94,7 & 41,8 & 96,0 & 44,2 & 46,0 \\
\hline \multirow{2}{*}{$\mathrm{Fe}$} & Seca & 749.633 & 632.219 & 558.719 & 262.400 & 550.743 & 207.686 & 37,7 \\
\hline & Chuva & 77.415 & 85.026 & 67.171 & 59.434 & 72.261 & 11.254 & 15,6 \\
\hline \multirow{2}{*}{$\mathrm{Mn}$} & Seca & 60,5 & 43,5 & 46,0 & 26,2 & 44,0 & 14,0 & 31,9 \\
\hline & Chuva & 38,5 & 38,7 & 45,7 & 29,1 & 38,0 & 6,80 & 17,9 \\
\hline \multirow{2}{*}{$\mathrm{Zn}$} & Seca & 251 & 204 & 251 & 66,6 & 193 & 87,6 & 45,2 \\
\hline & Chuva & 131 & 41,9 & 82,7 & 4,91 & 65,2 & 54,2 & 83,2 \\
\hline \multirow{2}{*}{$\mathrm{Hg}$} & Seca & 2,53 & 0,26 & 0,47 & 0,19 & 0,86 & 1,10 & 129 \\
\hline & Chuva & 0,23 & 0,22 & 0,35 & 0,15 & 0,24 & 0,08 & 34,9 \\
\hline
\end{tabular}

Tabela 5. Concentrações de elementos-traço determinados no solo do lixão de Porto velho - RO no período chuvoso e de seca. $\bar{x}$ : Média; DP: desvio padrão; CV: coeficiente de variação.

\begin{tabular}{|c|c|c|c|c|c|c|c|c|c|c|c|c|c|}
\hline $\begin{array}{l}\text { Elementos- } \\
\text { traço }\left(\mathrm{mg} \mathrm{kg}^{-1}\right)\end{array}$ & Período & LX1 & LX2 & LX3 & LX4 & LX5 & LX6 & LX7 & LX8 & LX9 & $\bar{x}$ & $\pm \mathbf{D P}$ & $\mathrm{CV}$ \\
\hline \multirow[t]{2}{*}{ Cd } & Seca & 0,03 & 0,30 & 0,20 & 0,02 & 0,07 & 0,37 & 0,09 & 0,02 & 2,70 & 0,42 & 1,28 & 302 \\
\hline & Chuva & 0,39 & 0,03 & 0,04 & 9,82 & 0,01 & 4,97 & 0,01 & 0,12 & 0,59 & 1,78 & 2,38 & 133 \\
\hline \multirow[t]{2}{*}{ Co } & Seca & 0,13 & 0,06 & 0,53 & 0,46 & 0,37 & 0,26 & 0,46 & 0,45 & 1,89 & 0,51 & 0,76 & 147 \\
\hline & Chuva & 2,65 & $<\mathrm{LDT}$ & $<\mathrm{LDT}$ & 14,9 & $<\mathrm{LDT}$ & 0,20 & $<\mathrm{LDT}$ & 2,38 & 1,34 & 4,30 & 1,09 & 25,4 \\
\hline \multirow[t]{2}{*}{$\mathrm{Cu}$} & Seca & 11,4 & 1,36 & 9,65 & 61,5 & 1,62 & 7,60 & 0,85 & 1,07 & 892 & 109 & 444 & 405 \\
\hline & Chuva & 66,8 & 2,18 & 2,41 & 1.251 & 4,01 & 336 & 0,76 & 9,36 & 185 & 206 & 159 & 77,5 \\
\hline \multirow[t]{2}{*}{$\mathbf{P b}$} & Seca & 6,12 & 21,1 & 6,35 & 49,2 & 6,60 & 30,7 & 6,05 & 3,08 & 213 & 38,0 & 100 & 264 \\
\hline & Chuva & 35,3 & 1,68 & $<\mathrm{LDT}$ & 427 & 0,32 & 305 & 0,67 & 7,72 & 14,8 & 99,2 & 148 & 150 \\
\hline \multirow[t]{2}{*}{$\mathrm{Cr}$} & Seca & 8,23 & 6,10 & 8,17 & 20,0 & 7,73 & 18,6 & 4,84 & 10,8 & 11,4 & 10,7 & 5,63 & 52,8 \\
\hline & Chuva & 19,4 & 5,07 & 4,95 & 109 & 4,19 & 74,5 & 4,50 & 9,11 & 7,58 & 26,5 & 33,7 & 127 \\
\hline \multirow[t]{2}{*}{$\mathrm{Fe}$} & Seca & 454.758 & 472.653 & 375.883 & 271.309 & 330.402 & 753.460 & 150.196 & 342.862 & 308.295 & 384.424 & 257.228 & 66,9 \\
\hline & Chuva & 66.545 & 73.402 & 64.865 & 104.448 & 58.343 & 92.402 & 24.817 & 82.896 & 62.193 & 69.990 & 29.957 & 42,8 \\
\hline \multirow[t]{2}{*}{ Mn } & Seca & 22,6 & 10,9 & 23,3 & 131 & 21,2 & 97,6 & 11,6 & 54,7 & 869 & 138 & 408 & 296 \\
\hline & Chuva & 102 & 9,03 & 13,2 & 477 & 8,73 & 601 & 5,83 & 32,6 & 18,7 & 141 & 291 & 206 \\
\hline \multirow[t]{2}{*}{$\mathbf{Z n}$} & Seca & 45,4 & 29,2 & 44,3 & 796 & 29,1 & 374 & 0,35 & 102 & 1.606 & 336 & 740 & 220 \\
\hline & Chuva & 595 & 4,82 & 63,7 & 1.736 & 11,6 & 1.285 & 239 & 518 & 134 & 510 & 519 & 101 \\
\hline
\end{tabular}


Tabela 6. Contribuição de cada variável (loadings) físico-química para as 3 principais componentes e a porcentagem de variância explicada no período chuvoso e de seca no igarapé dos Tanques. COMP: componente.

\begin{tabular}{l|c|c|c}
\hline Variáveis & \multicolumn{1}{c}{ COMP 1 } & \multicolumn{1}{c}{ COMP 2 } & COMP 3 \\
\hline Temperatura da Água & $-0,825$ & 0,321 & 0,292 \\
Condutividade Elétrica & $-0,844$ & $-0,233$ & 0,314 \\
$\mathrm{pH}$ & $-0,576$ & 0,376 & $-0,720$ \\
$\mathrm{O}_{2}$ Dissolvido & 0,323 & 0,883 & 0,283 \\
\% Variância explicada & 45,76 & 26,94 & 19,58 \\
\hline
\end{tabular}

Tabela 7. Contribuição de cada variável (loadings) para as 3 principais componentes e a porcentagem de variância explicada no período chuvoso e de seca para o sedimento superficial de fundo. COMP: componente.

\begin{tabular}{l|c|c|c}
\hline Variáveis & \multicolumn{1}{c}{ COMP 1 } & COMP 2 & COMP 3 \\
\hline$[\mathrm{Cd}]$ & 0.550 & -0.797 & -0.068 \\
{$[\mathrm{Co}]$} & 0.172 & -0.965 & -0.169 \\
{$[\mathrm{Cu}]$} & -0.535 & -0.604 & 0.453 \\
{$[\mathrm{~Pb}]$} & -0.603 & -0.705 & -0.303 \\
{$[\mathrm{Cr}]$} & 0.113 & -0.764 & 0.385 \\
{$[\mathrm{Fe}]$} & -0.906 & 0.396 & 0.129 \\
{$[\mathrm{Mn}]$} & -0.900 & -0.419 & -0.014 \\
{$[\mathrm{Zn}]$} & -0.899 & 0.178 & 0.194 \\
{$[\mathrm{Hg}]$} & -0.828 & -0.104 & -0.435 \\
$\%$ Variância explicada & 45.76 & 37.64 & 8.03 \\
\hline
\end{tabular}

de cada variável (loadings) geoquímica no solo do lixão. No período de seca a ACP ordenou as duas principais componentes totalizando $90,90 \%$ da variância. No período chuvoso, a primeira e a segunda componente explicaram $94,71 \%$ da variação dos dados. Os dados de Co não foram utilizados nesse período por estarem abaixo do LDT.

\section{DISCUSSÃO}

\section{Análise descritiva}

A capacidade de uma solução em conduzir a corrente elétrica é em função da concentração dos íons nela presentes (Esteves, 1998). Desse modo, o aumento na condutividade elétrica durante o período de seca pode ocorrer devido a maior concentração iônica. A mais alta condutividade elétrica encontrada no ponto IG4 pode estar relacionada ao fato deste ponto localizar-se em uma área mais central, recebendo influências não só de efluentes domésticos, mas também de efluentes oriundos de estabelecimentos comerciais.

Os maiores valores de $\mathrm{pH}$ ocorridos durante o período de seca podem estar associados à introdução de substâncias orgânicas (detergentes e sabão) provenientes de efluentes domésticos. Estas substâncias envolvem em sua fabricação uma base forte (hidróxido de sódio ou de potássio) e isso faz com que suas formulações apresentem um $\mathrm{pH}$ acima de 7 (Barbosa \& Silva, 1995). Estes podem reagir com a água fazendo com que haja um aumento no valor do $\mathrm{pH}$. Além disso, o período seco ajuda a manter esses valores, devido à diminuição da diluição.

Os menores valores de $\mathrm{pH}$ encontrados nos pontos IG2 e IG4 podem ser atribuídos à presença de ácidos orgânicos. Em geral, o pH de águas superficiais é alterado pelas concentrações de íons $\mathrm{H}+$ originados da dissociação de ácidos orgânicos como, por exemplo, o ácido carbônico, que geram baixos valores de $\mathrm{pH}$. Esse ácido carbônico nos corpos d'água é resultante da introdução de gás carbônico pelas águas de chuva, ar atmosférico e, principalmente, matéria orgânica que é consumida e oxidada nas águas (Esteves, 1998; Fiorucci et al, 2002).

É seguro afirmar que o grau de desoxigenação na água seja conseqüência da contribuição de matéria orgânica, através do lançamento de efluentes domésticos e esgotos sanitários sem tratamento e da elevada temperatura típica da região tropical. A

Tabela 8. Contribuição de cada variável (loadings) para as 3 principais componentes e a porcentagem de variância explicada no período chuvoso e de seca para o solo do lixão. COMP.: Componente.

\begin{tabular}{lcccccc}
\hline Variáveis & \multicolumn{3}{c}{ Seca } & \multicolumn{3}{c}{ Chuva } \\
& $\begin{array}{c}\text { COMP 1 1 } \\
\text { (loadings) }\end{array}$ & $\begin{array}{c}\text { COMP 2 } \\
\text { (loadings) }\end{array}$ & $\begin{array}{c}\text { COMP 3 } \\
\text { (loadings) }\end{array}$ & $\begin{array}{c}\text { COMP 1 1 } \\
\text { (loadings) }\end{array}$ & $\begin{array}{c}\text { COMP 2 } \\
\text { (loadings) }\end{array}$ & $\begin{array}{c}\text { COMP 3 } \\
\text { (loadings) }\end{array}$ \\
\hline$[\mathrm{Cd}]$ & $-0,968$ & 0,044 & 0,243 & $-0,983$ & $-0,137$ & 0,109 \\
{$[\mathrm{Co}]$} & $-0,960$ & 0,183 & $-0,043$ & - & - & - \\
{$[\mathrm{Cu}]$} & $-0,989$ & 0,089 & 0,102 & $-0,918$ & $-0,205$ & 0,338 \\
{$[\mathrm{~Pb}]$} & $-0,993$ & $-0,043$ & 0,040 & $-0,993$ & $-0,080$ & $-0,061$ \\
{$[\mathrm{Cr}]$} & $-0,229$ & $-0,849$ & $-0,474$ & $-0,996$ & $-0,074$ & $-0,033$ \\
{$[\mathrm{Fe}]$} & 0,167 & $-0,810$ & 0,561 & $-0,793$ & 0,591 & 0,150 \\
{$[\mathrm{Mn}]$} & $-0,997$ & $-0,004$ & 0,058 & $-0,925$ & 0,042 & $-0,366$ \\
{$[\mathrm{Zn}]$} & $-0,952$ & $-0,212$ & $-0,200$ & $-0,967$ & $-0,033$ & $-0,108$ \\
$\%$ Variância explicada & $72,56 \%$ & 18,34 & 8,20 & 88,65 & 6,06 & 4,27 \\
\hline
\end{tabular}


adição de matéria orgânica nos cursos d'água consome oxigênio dos mesmos através da oxidação química e principalmente da bioquímica, via respiração dos microrganismos, depurando assim a matéria orgânica e quando a carga de esgotos lançados excede a capacidade de autodepuração do corpo de água, este fica sem oxigênio (Valente et al., 1997). O fato dos maiores valores de oxigênio dissolvido serem encontrados durante o período chuvoso é conseqüência da homogeneização da coluna d'água provocada pela ação das chuvas.

Segundo a resolução CONAMA n ${ }^{\circ}$ 357, de 17 de março de 2005 , os valores de $\mathrm{pH}$ nos pontos IG2 (nos dois períodos) e IG4 (período de chuva) não se enquadram nos valores propostos para as águas de Classe $4(6,0$ a 9,0). Os valores médios de oxigênio dissolvido de 0,60 e $0,90 \mathrm{mg} \cdot \mathrm{L}^{-1}$ no período de seca e chuva, respectivamente, estão abaixo do valor mínimo de 2,0 mg.L $\mathrm{L}^{-1}$ estabelecido para esta mesma classe.

A maior contribuição para as concentrações de $\mathrm{Fe}$ no igarapé dos Tanques pode ter sido de origem natural, devido ao carreamento de partículas através dos processos de lixiviação. Cerca de 58\% dos solos do estado de Rondônia são classificados como latossolos, que possuem como característica a presença de altos teores de óxidos de ferro (Sedam, 2002). As concentrações de Mn também se destacaram e, segundo Fadigas et al. (2006), os latossolos são caracterizados por também apresentarem teores consideráveis deste elemento. Os demais elementos avaliados ( $\mathrm{Zn}, \mathrm{Cu}, \mathrm{Cr}, \mathrm{Co}, \mathrm{Cd}, \mathrm{Pb}$ e $\mathrm{Hg}$ ) provavelmente sejam provenientes da atividade antrópica, tais como os efluentes domésticos e comerciais, e do deflúvio superficial urbano lixiviado para o sistema aquático.

Os valores de $\mathrm{Cr}$ nas amostras de sedimento dos pontos IG1, IG2 e IG3 (período chuvoso) e de Hg no ponto IG1 (período de seca) ultrapassaram os valores de 90,00 mg $\mathrm{kg}^{-1}$ para $\mathrm{Cr}$ e $0,48 \mathrm{mg} \mathrm{kg}^{-1}$ para $\mathrm{Hg}$, que de acordo com a CETESB (2005a) são freqüentemente associados à efeitos biológicos adversos. O estudo de toxicidade em Hyalella azteca desenvolvido pela CETESB (2005a), revelou que estas concentrações provocaram a mortalidade de mais de $50 \%$ destes organismos. Além disso, foram observados outros efeitos como a deformidade e a redução no crescimento dos organismos.

Quanto aos níveis de elementos-traço no solo do lixão, a maior concentração média dos elementos no período chuvoso (exceto o $\mathrm{Fe}$ ) pode estar relacionada ao fato de que com o aumento da pluviosidade os metais tendem a se tornarem mais disponíveis no solo. Além disso, o chorume torna-se mais abundante e acaba carreando esses elementos com maior intensidade.

Os elevados valores de $\mathrm{Fe}$ em ambos os períodos indicam que além da presença de materiais que são potenciais fontes de ferro no lixão, mesmo em áreas que não receberam lixo (LX7), há também uma grande contribuição do tipo de solo da região para o incremento desses teores nas amostras. Quanto aos altos valores de zinco em alguns pontos (LX4 e LX6), pode-se inferir que estes estejam relacionados às fontes que contribuem para o aumento das concentrações deste elemento nestes locais de acordo com o que foi observado em campo, como materiais de borracha. Segundo Rousseaux (1992), esse tipo de material é responsável por 32 a $37 \%$ do $\mathrm{Zn}$ no composto de lixo urbano.

Os valores de zinco encontrados nos pontos LX1 e LX7 (no período de chuva) e LX4, LX6, LX7, LX8 e LX9 (nos dois períodos) foram maiores do que o valor de $79,00 \mathrm{mg} \mathrm{kg}^{-1}$, proposto como normal para latossolos não poluídos. Os pontos LX1 e LX2 no período de cheia e seca, respectivamente, apresentaram valores maiores que o valor de base sugerido para o elemento $\mathrm{Pb}\left(19,00 \mathrm{mg} \cdot \mathrm{kg}^{-1}\right)$ em latossolos. Os pontos LX4 e LX6 obtiveram concentrações maiores que os valores de base para Cd (1,00 mg kg-1), Cu (129,00 mg kg-1) e $\mathrm{Cr}$ $\left(55,00 \mathrm{mg} \mathrm{kg}^{-1}\right)$ no período de chuva e para $\mathrm{Pb}\left(19,00 \mathrm{mg} \mathrm{kg}^{-1}\right)$ em ambos os períodos (Fadigas et al., 2006).

Os teores mais elevados da maioria dos elementos (exceto $\mathrm{Cr}$ e $\mathrm{Fe}$ ) durante o período de seca foram encontrados no solo de uma das casas da Vila Princesa (LX9), o que pode estar associado ao fato do local já ter sido utilizado para deposição de lixo no passado. Neste período, as concentrações de $\mathrm{Cu}, \mathrm{Pb}$ e $\mathrm{Zn}$ excederam os valores de intervenção em solos utilizados para áreas agrícolas segundo a CETESB (2005b).

Tal constatação causa preocupação, uma vez que alguns dos moradores utilizam o mesmo para o plantio e retiram parte do sustento. Diante disso, o estado de Rondônia necessita, com certa urgência, estabelecer valores de elementos-traço de referência e intervenção para o controle e a qualidade do solo, para que através dos mesmos seja possível afirmar até que ponto determinadas áreas estão sofrendo influência destes elementos. Já no período de chuva as concentrações mais elevadas de todos os elementos foram observadas no ponto LX 4 (exceto $\mathrm{Mn}$ ), referente à uma célula que havia sido desativada há pouco tempo, podendo estar ainda sob influência do lixo outrora ali depositado.

\section{Análise de Componentes Principais (ACP)}

Na primeira componente da $\mathrm{ACP}$, as variáveis com as cargas mais elevadas foram para a condutividade elétrica e temperatura da água (Tabela 5). A condutividade elétrica expressa a quantidade de íons presentes na água, sendo esta quantidade influenciada pela temperatura. $\mathrm{O}$ aumento da temperatura catalisa a degradação da matéria orgânica através de reações metabólicas de microorganismos, disponibilizando íons para o ambiente (Valente et al., 1997; Fiorucci \& Benedetti Filho, 2005). É importante ainda ressaltar que a condutividade elétrica é influenciada pelos efluentes lançados no igarapé. Na segunda componente a variável com a carga mais elevada foi o oxigênio dissolvido. Esta é considerada importante porque através do decréscimo de sua concentração foi possível verificar a poluição orgânica do curso d'água evidenciando a influência antropogênica sobre o sistema aquático.

A primeira componente da ACP para as variáveis geoquímicas do sedimento é explicada pela maior relação entre as variáveis $\mathrm{Fe}, \mathrm{Mn}, \mathrm{Zn}$ e $\mathrm{Hg}$, sendo determinada como 
a "componente dos processos geoquímicos". Os óxidos de $\mathrm{Fe}$ e Mn, presentes naturalmente nos solos, são bons carreadores de elementos-traço do meio. Estes podem estar carreando os elementos $\mathrm{Zn}$ e $\mathrm{Hg}$ presentes no deflúvio superficial urbano, que geralmente contém todos os poluentes que se depositam na superfície dos solos.

$\mathrm{Na}$ segunda componente, as variáveis que mais contribuíram foram $\mathrm{Cd}, \mathrm{Co}, \mathrm{Pb}, \mathrm{Cu}$ e $\mathrm{Cr}$ sendo classificada como antropogênica, uma vez que estes elementos são encontrados no ambiente em baixas concentrações e no igarapé os mesmos apresentaram-se em concentrações elevadas.

A ACP para as variáveis geoquímicas do sedimento superficial de fundo mostrou que a introdução de elementostraço no igarapé dos Tanques ocorre através do carreamento de partículas pelos óxidos de $\mathrm{Fe}$ e Mn e através da introdução de efluentes domésticos e comerciais, como resultado das diversas atividades desenvolvidas na região, principalmente o intenso uso do solo.

Quanto à $\mathrm{ACP}$ do lixão no período de seca, a primeira componente agrupou os elementos $\mathrm{Mn}, \mathrm{Pb}$ e $\mathrm{Cu}$ (Tabela 7) sendo considerada como componente antropogênica. De acordo com a literatura, $\mathrm{o} \mathrm{Pb}$ e $\mathrm{Cu}$ são considerados traçadores antrópicos, podendo indicar a contaminação de áreas por diversas atividades. $\mathrm{O} \mathrm{Mn}$ pode ter sido associado ao $\mathrm{Pb}$ e $\mathrm{Cu}$ porque alguns pontos apresentaram teores muito maiores do que os encontrados em outras áreas da região aparentemente menos impactadas, como é o caso do ponto LX 7. Além disso, a disponibilidade do $\mathrm{Pb}$ e $\mathrm{Cu}$ depende da presença de outros íons, como o Mn, capazes de deslocá-los. Sendo assim, as concentrações de Mn podem estar relacionadas aos processos biogeoquímicos do solo e, nesse caso, também à contaminação oriunda de materiais que contém esse elemento, tais como pilhas comuns, alcalinas e as lâmpadas fluorescentes (Leinz \& Amaral, 1995; Segato \& Silva, 2000). A segunda componente é explicada pela maior relação com a variável $\mathrm{Cr}$ e em menor relação com a variável $\mathrm{Fe}$. A mesma é classificada como componente eixo de transporte, uma vez que o $\mathrm{Cr}$ pode se apresentar mais ligado às frações de óxidos e hidróxidos de $\mathrm{Fe}$, que acaba servindo como um elemento carreador deste metal (Hypolito \& Nascimento, 2004).

No período chuvoso, observou-se que a primeira componente agrupou o $\mathrm{Pb}$, o $\mathrm{Cr}$ e o $\mathrm{Cd}$ sendo também classificada como antrópica. $\mathrm{O} \mathrm{Cr}$ pode ter sido agrupado na primeira componente em conseqüência de ter apresentado valores elevados em alguns pontos (LX4 e LX6). Apesar do $\mathrm{Cd}$ ter apresentado a menor concentração média de todos os metais no período chuvoso, o mesmo pode ter sido agrupado na primeira componente por ter apresentado concentrações consideráveis em pontos como LX4 e LX6. A segunda componente apresentou a maior carga para o Fe e foi caracterizada como componente regional, associado ao tipo de solo da região (latossolo). Acredita-se que outro fator que também contribui para estes elevados teores são as grandes quantidades de latas depositadas no local. Essas latas ao serem incineradas, se oxidam e liberam partículas de óxidos metálicos que podem se aderir à matéria orgânica úmida ou podem ser lixiviados da fração inorgânica para a orgânica.

\section{CONSIDERAÇÕES}

Os resultados obtidos ressaltam que apesar da recente ocupação de Porto Velho, a cidade pode apresentar em um curto período de tempo um quadro de degradação ambiental semelhante ao de grandes centros urbanos, caso não adote um novo modelo de desenvolvimento. As informações geradas têm um importante significado no sentido de direcionar para a necessidade de se articular ações com o objetivo de tentar solucionar problemas ambientais, que por sua vez guardam estreita relação com a saúde humana e com a qualidade de vida.

É importante salientar que este quadro ambiental tende a sofrer um agravamento com a construção das Usinas Hidrelétricas de Jirau e Santo Antônio no rio Madeira, devido ao provável aumento populacional que acontecerá em função da instalação das mesmas e da falta de infraestrutura da cidade para acompanhar tal crescimento.

\section{AGRADECIMENTOS}

Os autores agradecem o apoio financeiro do Conselho Nacional de Desenvolvimento Cientifico e Tecnológico (CNPq) através dos projetos $\mathrm{MCT} / \mathrm{CNPq} / \mathrm{CT}$-Amazônia (Proc. No. 553269/2005-4) e MCT/CNPq/PPG-7-Fase II (Proc. No. 556934/2005-9). Somos agradecidos também ao apoio da Comunidade da Vila Princesa.

\section{REFERÊNCIAS}

ADAMY, A. \& PEREIRA, L. A. C., 1991, Projeto Ouro Gemas frente Rondônia. Companhia de pesquisa e recursos minerais CPRM, Porto Velho, RO, 46 p.

BASTOS, W.R., MALM, O., PFEIFFER, W. \& CLEARY, D., 1998, Establishment and analytical quality control of laboratories for $\mathrm{Hg}$ determination in biological and geological samples in the Amazon - Brazil. J. Braz. Assoc. Adv. Sci., 50: 255 - 260.

BAIRD, C., 2002, Química ambiental. $2^{\mathrm{a}}$ ed. Artmed Bookman, Porto Alegre, $622 \mathrm{p}$.

BARBOSA, A. \& SILVA, R. R., 1995, Xampus. Quím. Nova na escola, 2: 3-5.

BERNARDI, J.V., FOWLER, H. G. \& LANDIM, P. M. B., 2001, Um estudo de impacto ambiental utilizando análises estatísticas espacial e multivariada. Holos Environment., 1: 162 - 172.

BONOTTO, D.M. \& SILVEIRA, E.G., 2003, Preference ratios for mercury and other chemical elements in the Madeira River, Brazil. J. S. Am. Earth Sci., 15: 911-923. doi: http://dx.doi. org/10.1016/S0895-9811(02)00144-X.

BRASIL, 2005, Resolução $n^{\circ}$ 357, 17 de março de 2005. Dispõem sobre a classificação dos corpos de água e diretrizes ambientais para o seu enquadramento, bem como estabelece as condições e padrões de efluentes, e dá outras providências. Diário Oficial da União, Brasília, 18 de março 2005, p. 58-63.

CETESB - Companhia de Tecnologia de Saneamento Ambiental. 1987, Guia de coleta e preservação de amostras de água, São Paulo, SP, 197 p. 
CETESB - Companhia de Tecnologia de Saneamento Ambiental. 2005 (a), Relatório de qualidade das águas interiores no Estado de São Paulo, 307 p.

CETESB, Companhia de Tecnologia de Saneamento Ambiental. 2005 (b), Estabelecimento de Valores Orientadores para Solos e Águas Subterrâneas no Estado de São Paulo, 4 p.

ESTEVES, F.A., 1998, Fundamentos de Limnologia. $2^{\text {a }}$ ed. Interciência, Rio de Janeiro, 601p.

EZAKI, S., HYPOLITO, R. \& KOMATI, D.T., 2003, Comportamento de íons de metais pesados associados a solos de cobertura diária de resíduos sólidos em aterro sanitário. IX Congresso brasileiro de geoquímica, 49-54, Belém - PA.

FADIGAS, F. S., AMARAL SOBRINHO, N.M.B., MAZUR, N., ANJOS, L. H. C. \& FREIXO, A. A., 2006, Proposição de valores de referência para a concentração natural de metais pesados em solos brasileiros. Rev. Bras. de Eng. Agrícola e Ambiental, 10: 699-705.

FIORUCCI, A. R. \& BENEDETTI, E. F. A., 2005, A importância do oxigênio dissolvido em ecossistemas aquáticos. Quím. Nova na Escola, 22: 10-16.

HYPOLITO, R. \& NASCIMENTO, S. C., 2004, Comportamento de íons metálicos em solos, sedimentos, águas superficiais e subterrâneas no Córrego da Anta, S. J. do Rio Preto - SP. Rev. Águas Subt., 18: 55 - 65.

JESUS, H.C., COSTA, E.A., MEDONÇA, A. S. F. M \& ZANDONADE. E., 2004, Distribuição de metais pesados em sedimentos do sistema estuarino da ilha de Vitório-Es. Quím. Nova, 27: 378-386. doi: http://dx.doi.org/10.1590/S010040422004000300004.

LANDIM, P.M.B., 1998, Análise estatística de dados geológicos. UNESP, São Paulo, 226 p.

LEINZ, V.; AMARAL, S. E, 1995, Geologia geral. 12ª ed. Nacional, São Paulo, 397p.

PEDLOWSKI, M., DALE, V. \& MATRICARDI, E., 1999, A criação de áreas protegidas e os limites de conservação ambiental em Rondônia. Amb. e Socied, 5: 93-253. doi: http://dx.doi. org/10.1590/S1414-753X1999000200008.

ROBAINA, L.E., FORMOSO, M.L.L. \& PIRES, C.A.F., 2002, Metais pesados nos sedimentos de corrente, como indicadores de risco ambiental - vale do rio dos sinos, RS. Rev. do Inst. Geologia de São Paulo, 23: 35-47.
ROUSSEAUX, P., CASTILHOS A. B., VERMANDE P. \& VERON, J., 1992, Determination of trommel meshes for optimal separation of compostible fraction of municipal solid wastes from Florianópolis, SC, Brazil. Resour. Conserv. and Recycling, 6: 217-229. doi: http://dx.doi.org/10.1016/09213449(92)90032-W.

SASTRE, J., SAHUQUILLO, A., VIDAL, M. \& RAURET, G., 2002, Determination of $\mathrm{Cd}, \mathrm{Cu}, \mathrm{Pb}$ and $\mathrm{Zn}$ in environmental samples: microwave-assisted total digestion versus aqua regia and nitric acid extraction. Anal. Chim. Acta, 462: 59-72. doi: http://dx.doi. org/10.1016/S0003-2670(02)00307-0.

SEDAM, Secretaria de Estado de Desenvolvimento Ambiental, 2002. Atlas Geoambiental de Rondônia. Porto Velho, RO, 141p.

SEGATO, L. M.S \& SILVA, C. L., 2000, Caracterização do Chorume do Aterro Sanitário de Bauru. In: XXVII Congresso Interamericano de Engenharia Sanitária e Ambiental - AIDIS, 2000, Porto Alegre - RS. XXVII Congresso Interamericano de Engenharia Sanitária e Ambiental. Rio de Janeiro : Editora ABES.

SIOLI, H., 1991, Amazônia: fundamentos da ecologia da maior região de florestas tropicais, Vozes, Rio de Janeiro, 72p.

SISINNO, C. L. S. \& MOREIRA, J.C., 1996, Avaliação da contaminação e poluição ambiental na área de influência do aterro controlado do Morro do Céu, Niterói, Brasil. Cad. Saúde Pública, 12: 515-523. doi: http://dx.doi.org/10.1590/S0102311X1996000400010.

SIQUEIRA, G. W., PEREIRA, S.F.P. \& APRILE, F.M., 2006, Determinação dos elementos-traço (Zn, Co e Ni) em sedimentos da Plataforma Continental Amazônica sob influência da descarga do rio Amazonas. Acta Amaz., 36: 321 - 326. doi: http://dx.doi. org/10.1590/S0044-59672006000300005

VALENTE, J. P. S., PADILHA, P. M. \& SIVA, A. M. M., 1997, Oxigênio dissolvido (OD), demanda química de Oxigênio (DQO) como parâmetros de poluição no Ribeirão Lavapés/Botucatu SP. Eclét. Quím., 22: 1-13. doi: http://dx.doi.org/10.1590/S010046701997000100005.

YABE, M. J. S. \& OLIVEIRA, E., 1998, Metais pesados em águas superficiais como estratégia de caracterização de bacias hidrográficas. Quím. Nova, 21: 551-556. doi: http://dx.doi. org/10.1590/S0100-40421998000500003. 